\title{
Peroral cholangioscopy of nivolumab-related (induced) ulcerative cholangitis in a patient with non-small cell lung cancer
}

Approximately $10 \%-15 \%$ of patients treated with nivolumab may develop grade 3/4 immuno-related adverse events (irAEs) [1-3]. Rash and diarrhea are the common irAEs, whereas there have been few reports of nivolumabrelated cholangitis and its clinical features [4].

A 69-year-old male patient with advanced lung adenocarcinoma had been treated with nivolumab as third-line chemotherapy. After the third course of nivolumab, he complained of pruritic rash. His laboratory data showed increased liver and biliary tract enzymes. He was treated with oral prednisolone at a dose of $60 \mathrm{mg}$ a day. As his medical condition was not improved by steroid therapy, he was referred to our department.

Computed tomography showed diffuse hypertrophy of extrahepatic bile ducts without any obstruction, such as stones or malignancies ( $\mathbf{F i g} . \mathbf{1}$ ). Endoscopic ultrasonography showed slight dilation of the extrahepatic bile ducts without obstruction ( Fig.2). Endoscopic retrograde cholangiopancreatography showed that the epithelium of the bile duct was irregular and coarse ( Fig.3). After endoscopic sphincterotomy had been performed, peroral cholangioscopy revealed that the epithelium of the extrahepatic bile duct was erosive and bled easily, with many black spots and inflammation, giving a "burnedout" appearance ( $\triangleright$ Fig.4, $>$ Video 1 ).

A biopsy of the lesions of the extrahepatic bile duct showed infiltrating inflammatory cells in the bile duct epithelium ( $\triangleright$ Fig.5).

As the patient's liver toxicity worsened despite the treatment with oral prednisolone, intravenous methyl-prednisolone treatment $(500 \mathrm{mg} /$ day) was started, but this also failed to improve his condition. He died from nivolumabrelated cholangitis 3 months after the start of treatment.

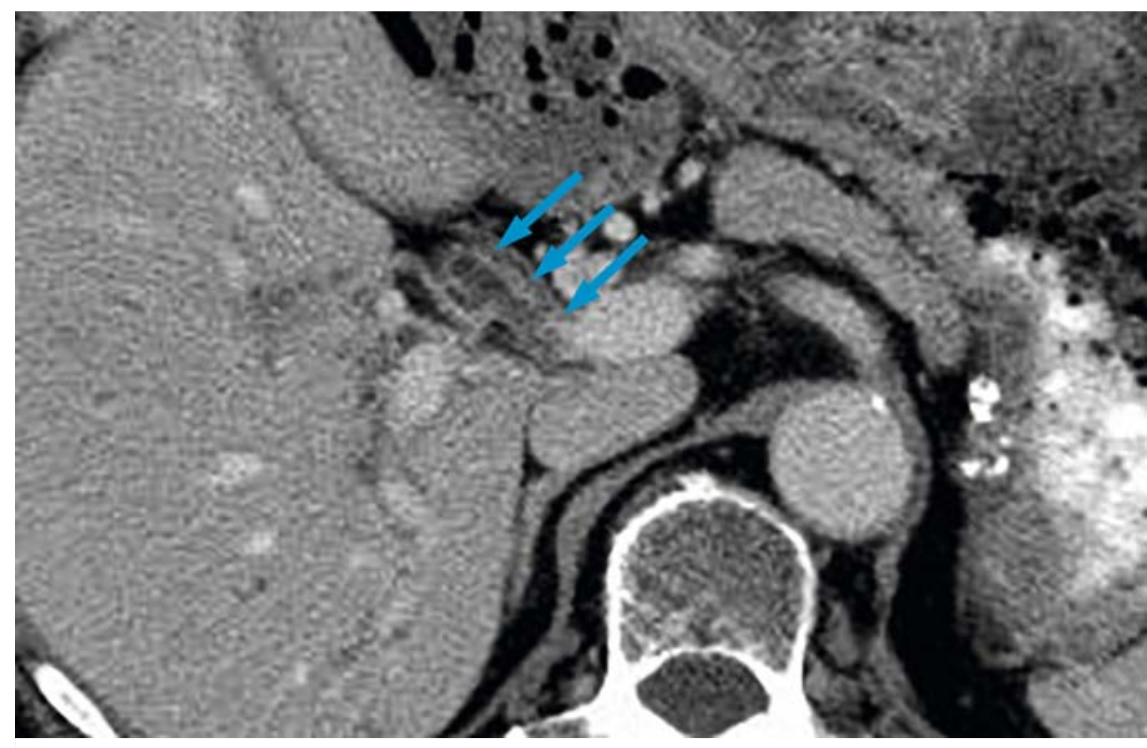

- Fig. 1 Computed tomography showed diffuse hypertrophy (arrows) of extrahepatic bile ducts. There was no obstruction or stenotic sites in the distal bile duct.

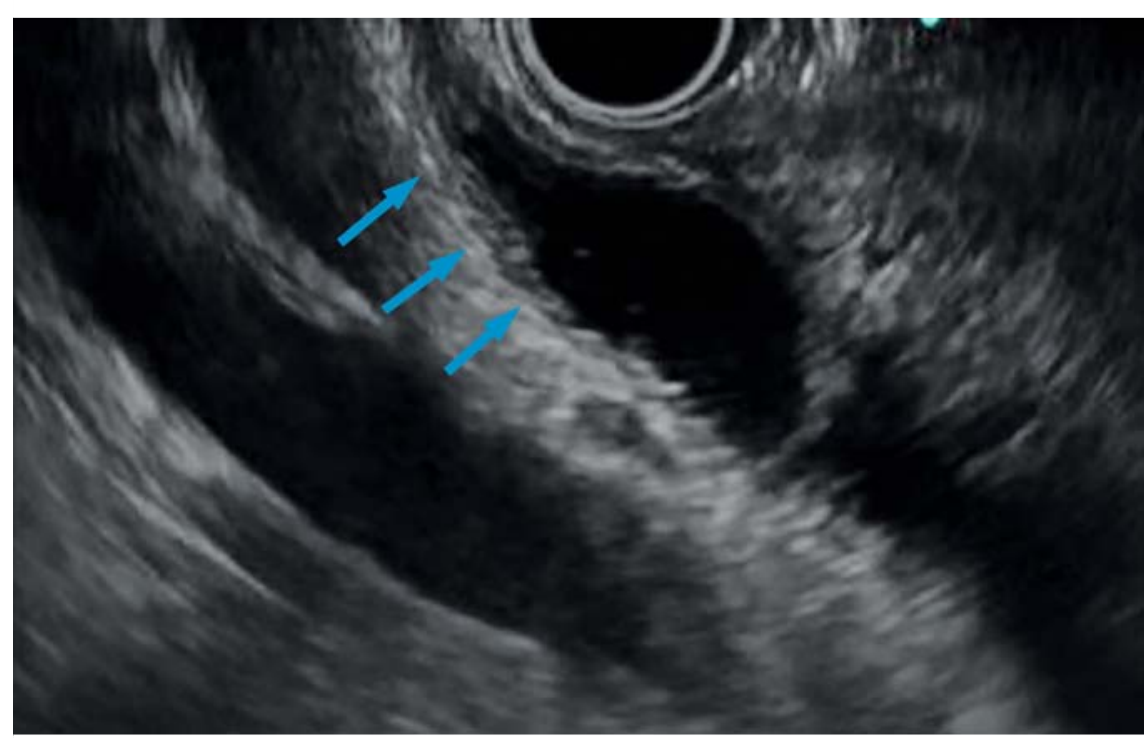

Fig. 2 Endoscopic ultrasound showed diffusely coarse epithelium of the extrahepatic bile duct (arrows).

In this case, peroral cholangioscopy showed ulcerative lesions with the "burned-out" epithelium of the extrahepatic bile duct, which was erosive and bled easily. The pathology revealed infiltrating inflammatory cells in the bile duct epithelium, suggesting that the lymphocytes affected by nivolumab might attack the epithelial cells and/or microvessels of the bile duct.

Endoscopy_UCTN_Code_CCL_1AZ_2A 

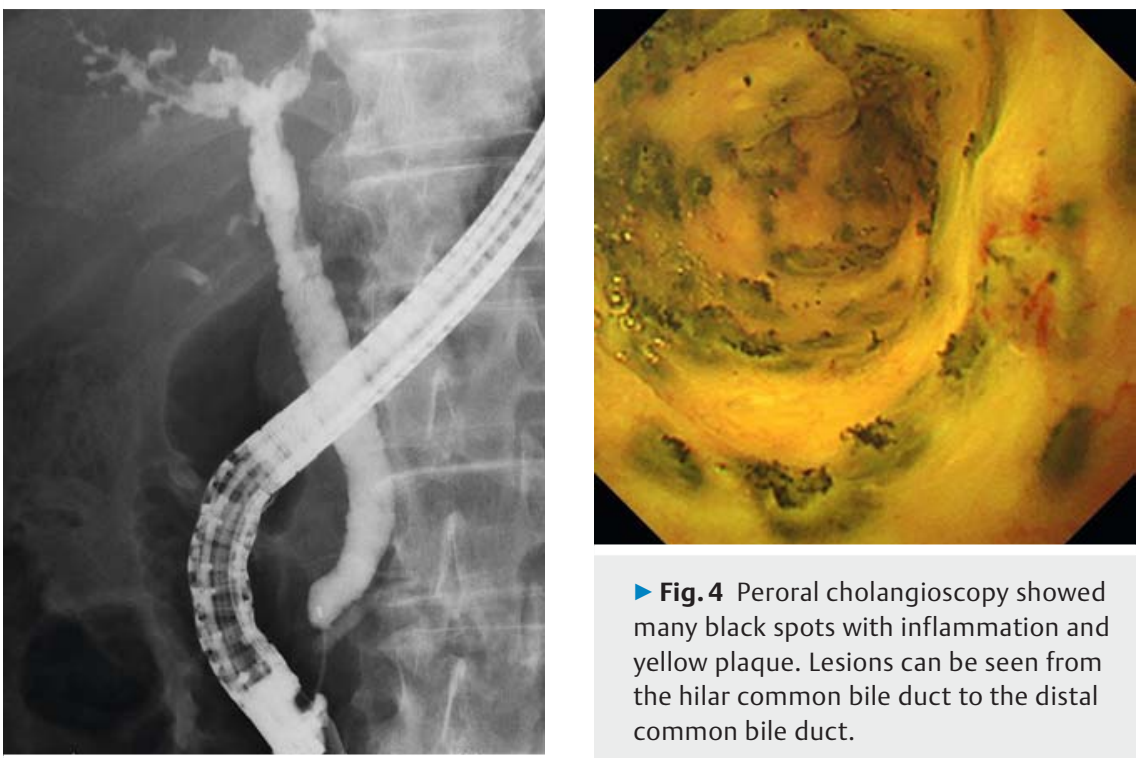

Fig. 4 Peroral cholangioscopy showed many black spots with inflammation and yellow plaque. Lesions can be seen from the hilar common bile duct to the distal common bile duct.
Competing interests

None

The authors

Naosuke Kuraoka, ${ }^{1,2}$, Kazuo Hara ${ }^{1}$, Shuji Terai $^{2}$, Yasushi Yatabe ${ }^{3}$, Yoshitsugu Horio ${ }^{4}$

1 Department of Gastroenterology, Aichi Cancer Center Hospital, Nagoya, Japan

2 Department of Gastroenterology and Hepatology, Graduate School of Medical and Dental Sciences, Niigata University, Niigata, Japan

3 Department of Pathology and Molecular Diagnostics, Aichi Cancer Center Hospital, Nagoya, Japan

4 Department of Thoracic Oncology, Aichi Cancer Center Hospital, Nagoya, Japan

Corresponding author

giopancreatography showed the coarse image of the extrahepatic bile duct without obstruction.

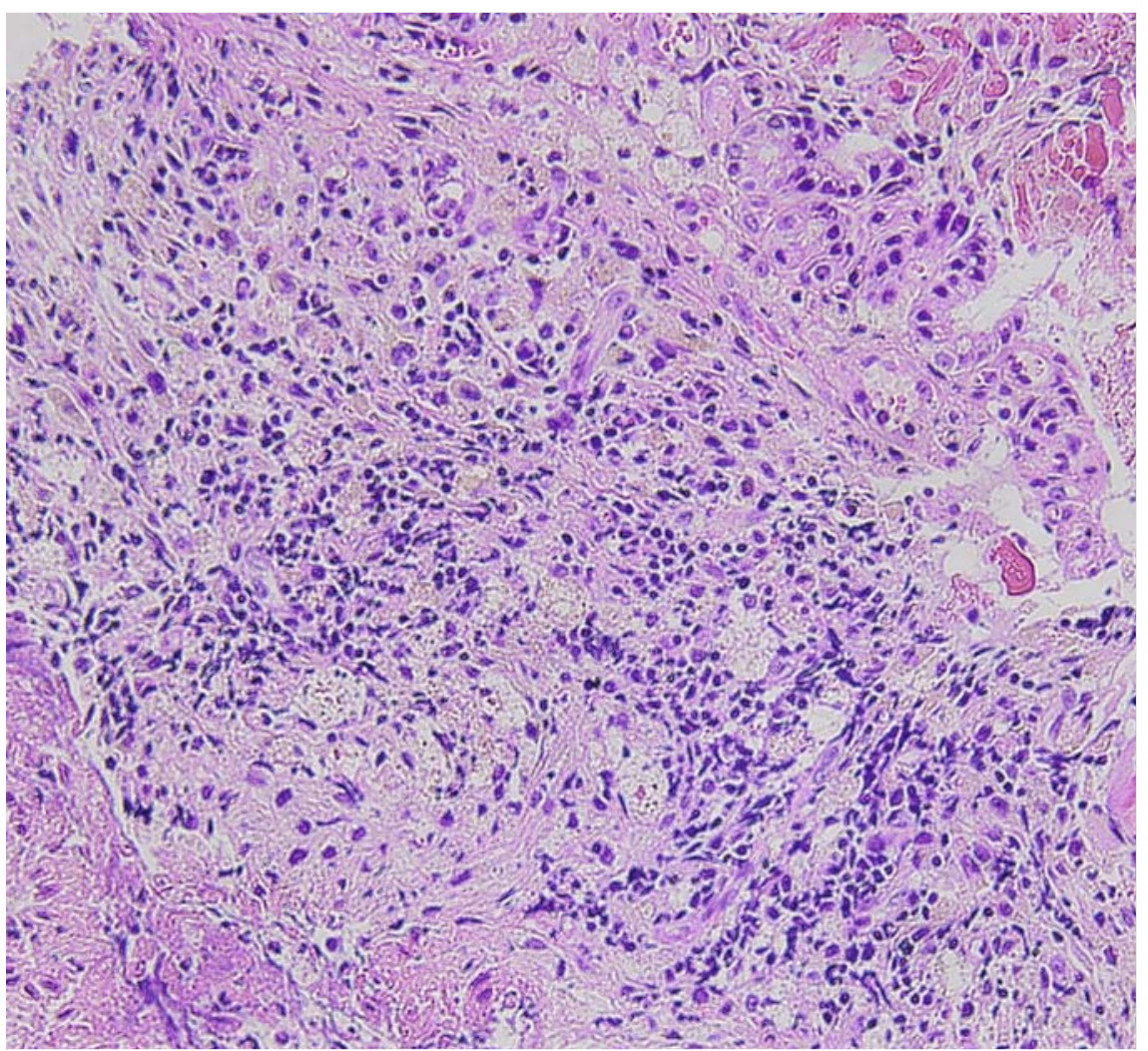

Kazuo Hara, MD, PhD

Department of Gastroenterology, Aichi Cancer Center, Kanokoden, Chikusa-ku, Nagoya, Aichi, 464-8681, Japan

Fax: +81-52-7635233

khara@aichi-cc.jp

\section{References}

[1] Brahmer ], Reckamp KL, Baas P et al. Nivolumab versus docetaxel in advanced squamous cell non-small-cell lung cancer. $\mathrm{N}$ Engl J Med 2015; 373: 123-135

[2] Borghaei H, Paz-Ares L, Horn L et al. Nivolumab versus docetaxel in advanced nonsquamous non-small-cell lung cancer. $N$ Engl J Med 2015; 373: 1627 - 1639

[3] Spain L, Diem S, Larkin J. Management of toxicities of immune checkpoint inhibitors. Cancer Treat Rev 2016; 44: 51-60

[4] Kawakami H, Tanizaki J, Tanaka K et al. Imaging and clinicopathological features of nivolumab-related cholangitis in patients with non-small cell lung cancer. Invest New Drugs 2017; 35: 529-536
- Fig. 5 Inflammatory cells and lymphocytes infiltrated the epithelium of the extrahepatic bile duct. 


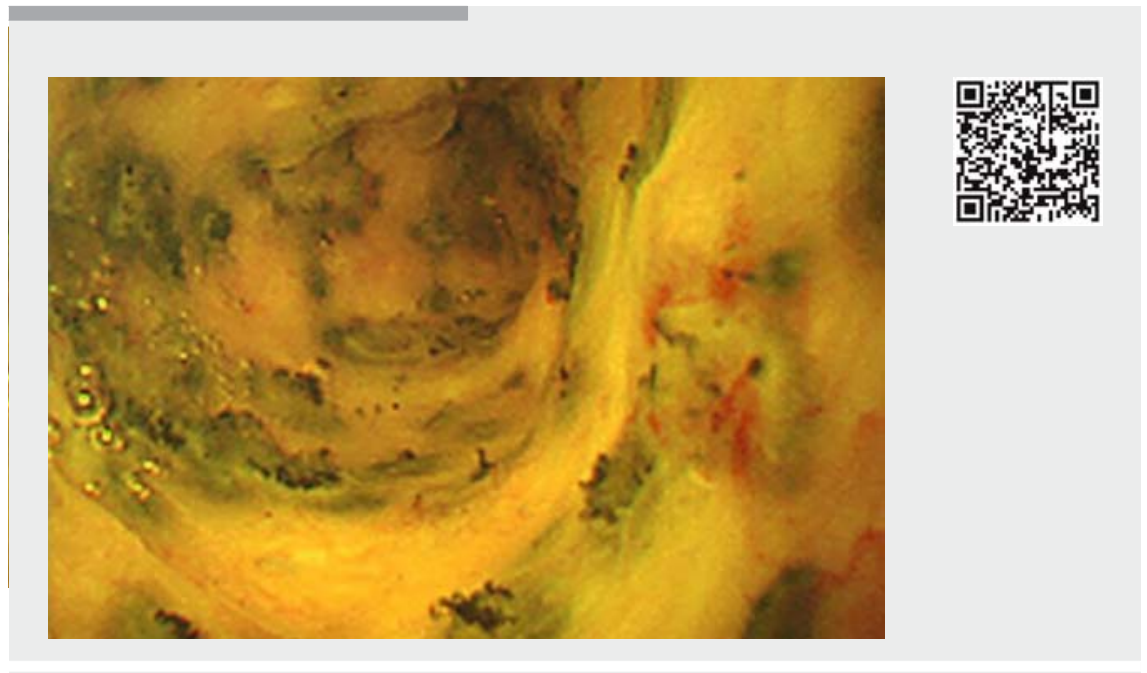

$\checkmark$ Video 1 Peroral cholangioscopy of nivolumab-related ulcerative cholangitis.

\section{Bibliography}

DOI https://doi.org/10.1055/a-0640-2392

Published online: 3.7.2018

Endoscopy 2018; 50: E259-E261

(c) Georg Thieme Verlag KG

Stuttgart · New York

ISSN 0013-726X

\section{ENDOSCOPY E-VIDEOS}

https:|/eref.thieme.de/e-videos

口回 Endoscopy E-Videos is a free access online section, reporting 自: on interesting cases and new techniques in gastroenterological endoscopy. All papers include a high quality video and all contributions are freely accessible online.

This section has its own submission website at

https://mc.manuscriptcentral.com/e-videos 